\title{
O general, a catedral e o "filósofo": reflexões acerca do papel do medievalista diante de seus novos públicos
}

\author{
The general, the cathedral and the "philosopher": reflections on the Medievalist's role \\ towards their new publics \\ Carlile Lanzieri Júnior \\ https://orcid.org/0000-0002-7190-6809 \\ Universidade Federal de Mato Grosso
}

Resumo: Construir explicações plausíveis e éticas acerca do passado humano tendo como base a documentação disponível. Esta é a função primordial do historiador. Todavia, ao longo da história, percebe-se que tal premissa nem sempre norteou a construção das narrativas daqueles que tomaram o passado como objeto de pesquisa. Manipulações com vistas à construção de ideologias (muitas vezes preconceituosas e violentas) foram recorrentes, sobretudo em momentos de crise econômica e consternação social. Em relação a períodos mais distantes e desconhecidos por parte do grande público, como a Idade Média, tais ações ganham ainda mais força. Com o advento e avanço das redes sociais, as possibilidades tornaram-se praticamente infinitas. Analisar algumas das formas pelas quais o passado medieval foi tomado com intenções voltadas para contextos específicos da atualidade, assim como as relações de força por trás desses usos é a proposta central deste trabalho que também destaca a necessidade do historiador compreender e dialogar com seus novos públicos a partir de novas linguagens.

Palavras-chave: Medievalismo. Pós-verdade. Usos do passado.

Abstract: Carving out plausible and ethic explanations concerning the human past having as its base the available documentation. This is the historian's primordial duty. Howbeit, throughout the history, it is possible to perceive that such premise not always guided the narratives construction of those who took the past as an object of research. Manipulations with a view to ideologies building (many times biased and violent) have been recurring, mostly in times of economic crisis and social consternation. As for more distant and unknown by most people periods, as Middle Ages, such actions gain even more strength. Analyzing some ways through which the medieval past was taken with intentions aiming at specific contexts of the present time, as well as the power struggle which underlie such uses is the core purpose of this essay which also emphasizes the need of the historian understanding and dialoguing with their new publics as from new languages.

Keywords: Medievalism. Post truth. Uses of the past.

\begin{abstract}
"Se não estudamos a Idade Média, e não tentamos entendê-la e explicá-la de uma maneira imparcial, deixaremos então o campo aberto para aqueles que abusam e exploram o passado para justificar injustiças modernas" (Gabor Klaniczay adaptado por Graham A. Loub e Martial Staub)
\end{abstract}




\section{O passado é promíscuo}

“[...] são os historiadores que criam 'a história' e que 'o passado' de onde eles esculpem sentidos é totalmente promíscuo. O passado sempre foi e sempre irá com qualquer um, sem sombra de ciúme nem pitada de fidelidade permanente a uma determinada pessoa [...]". O pequeno extrato com o qual inicio este ensaio foi sacado do livro A história refigurada do historiador britânico Keith Jenkins (2014, p. 21). Ao me alinhar com o que Jenkins afirmou há alguns anos e diante do que pretendo aqui debater, não posso negar o fato de que o passado vai com todos mesmo. É de sua índole. $\mathrm{E}$ assim sempre será até que não mais tenhamos humanos a caminhar por este planeta.

Com pitadas aqui e ali do discreto humor britânico, as assertivas deixadas por Keith Jenkins em seu pequeno livro de cunho teórico encaixam-se muito bem naquilo que um outro historiador também de origem inglesa asseverou em palestra proferida na Universidade da Europa Central na cidade de Budapeste, capital da Hungria, nos idos dos anos 90 do século passado. Seu nome: Eric Hobsbawm (1917-2012). Suas palavras: "Eu costumava pensar que a profissão de historiador, ao contrário, digamos, da de físico nuclear, não pudesse, pelo menos, produzir danos. Agora sei que pode" (HOBSBAWM, 1998, p. 17). Sim, ela pode.

Keith Jenkins e Eric Hobsbawm, dois historiadores da velha cepa assaz lidos e relidos nos cursos de História que ainda resistem em nosso país. Entre eles, uma nítida evidência: a certeza de que a dimensão ética no ofício de historiador e dos humanistas em geral não pode ser ignorada. Algo que não necessariamente orienta os trabalhos dos enamorados pela História, graduados ou não, jovens ou não. Portanto, por mais que tenhamos o sagrado direito de fazer livremente nossas escolhas político-partidárias, deliberadamente contaminar de maneira ideológica as pesquisas que produzimos com o intento de fazer propaganda não é um bom negócio. É um equívoco! Em outras palavras, é fazer uma História menor, uma história com "h" minúsculo. E essa brincadeira pode se tornar assustadoramente perigosa. É preciso estar atento.

Com o crescimento acelerado das redes sociais e o desenvolvimento de novas formas de expressão como, entre outras, memes, blogs e pequenos vídeos caseiros aninhados majoritariamente no YouTube, os novos formadores de opinião (digital influencers, no jargão próprio do mundo virtual) assumiram um papel antes destinado basicamente a professores, escritores, jornalistas e pesquisadores. Não raramente, estes tornaram-se objeto de desprezo (D'ANCONA, 2018, p. 19). Da noite para o dia, milhões de pessoas começaram a emitir e reproduzir opiniões nesses novos espaços e sem critério algum, a não ser as aguardadas curtidas (que também podem ser compradas aos milhares por uma pequena soma em dinheiro...). Assustadoramente, a força de uma boa argumentação perdeu terreno para o número de clicadas positivas e compartilhamentos de uma simples publicação com frases de efeito, dados fantasiosos e fontes duvidosas. Como consequência, essa passou a ostentar status de verdade não pela qualidade dos conteúdos em si, mas pela quantidade de vezes que circulou pelos meandros mais recônditos da Internet. Nesta levada impulsiva (ou compulsiva...), a razão honestamente complexa foi tomada de assalto pela emoção visceral e simples que passou a nortear os debates públicos (2018, p. 29). Não me posiciono contra essa 
nova realidade, caro(a) leitor(a): ela chegou para ficar e com ela muito podemos aprender. Minha inquietação se faz quando há a imposição pura e simples de narrativas desejáveis e que para tanto se valem de todo tipo de inversões e negacionismos.

Em seu livro O filtro invisível, Eli Pariser (1980- ) fez um importante alerta: da maneira como hoje se desenvolvem, as redes sociais são capazes de processar informações para criar e alimentar bolhas ideológicas através dos algoritmos (PARISER, 2012, p. 14). ${ }^{1}$ Alguns cliques aparentemente inocentes e algumas horas de navegação entre um site e outro são mais do que suficientes para que os manipuladores invisíveis das redes tenham condições de traçar com razoável precisão o perfil do usuário. E se este tende a ser simpático, por exemplo, a orientações políticas de conteúdo fascista ou qualquer teoria conspiratória, ele passa a ser alimentado dia a dia com notícias com temáticas semelhantes. Em pouco tempo, este até então desavisado usuário ganha coragem e se torna um potente reprodutor dessas informações que para ele funcionam como verdades inquestionáveis, mesmo que bibliotecas inteiras tenham milhares de livros que lhe digam exatamente o contrário e a partir de pontos-de-vista assaz variados.

Não por acaso, emergiu deste mesmo contexto um conceito que vem sendo debatido diariamente dentro e fora das universidades e outros espaços destinados à transmissão e produção de conhecimento: a pós-verdade. Escolhida como a palavra do ano de 2016 pelo Dicionário Oxford, a pós-verdade tem chamado cada vez mais a atenção de pesquisadores de diferentes áreas em diversas partes do mundo. De psicólogos a escritores, passando por jornalistas, filósofos e historiadores, ela tem sido usualmente definida não apenas como um boato ou uma mentira, mas como uma espécie de verdade paralela que conforta sem confrontar as opiniões prévias de um indivíduo. Como corolário, a pós-verdade impõe o silêncio à ciência e a amplificação de toda sorte de ideologias regadas com quantidades massivas de fatos alternativos. ${ }^{2}$ Com a rapidez exponencial comum ao mundo tecnológico, ela não permite o contraditório, uma lufada de incertezas. Ao entregar quantidades absurdas de informações prontas que surgem e se propagam de um perfil de um usuário ao outro como um rastilho de pólvora, a pós-verdade ergue barreiras que impedem que os benefícios da dúvida se manifestem.

Em tese, a pós-verdade não é uma novidade entre nós. De fato, criar artifícios retóricos repetitivos para acusar ou infamar a imagem de alguém ou algum acontecimento já era comum nos textos de cristãos nos quais apareciam, por exemplo, as figuras animalescas do infiel ou do judeu traidor (WHEATCROFT, 2002, p. 126-134). Tal recurso de apelo emotivo também teve presença garantida na primeira metade do século XX, quando nazistas violentamente reduziram toda a diversidade da cultura judaica a uma identidade única expressa pela palavra "judeu" então totalmente estigmatizada (TODOROV, 2010, p. 81). Com efeito, quem é considerado um nada ou algo muito próximo disso por parte de seus algozes pode ser humilhado, encarcerado, espancado ou mesmo morto sem produzir peso algum para a consciência dos executores de tais ações. Os exemplos macabros de tais manipulações são fartamente

\footnotetext{
1 "O código básico no seio da nova internet é bastante simples. A nova geração de filtros on-line examina aquilo de que aparentemente gostamos - as coisas que fazemos, ou as coisas das quais as pessoas parecidas conosco gostam - e tenta fazer extrapolações. São mecanismos de previsão que criam e refinam constantemente uma teoria sobre quem somos e sobre o que vamos fazer ou desejar a seguir. Juntos, esses mecanismos criam um universo de informações exclusivo para cada um de nós - o que passei a chamar de bolha dos filtros - que altera fundamentalmente o modo como nos deparamos com ideias e informações" (Pariser, 2012, p. 14).

2 Cf. D'Ancona, 2018, p. 15 e 19; Dunker, 2017, p. 35 e 39.
} 
conhecidos. ${ }^{3}$ Dito de maneira mais simples: basta crer para destruir. Todavia, o alcance dessas verdades sempre foi restrito a regiões e a grupos específicos. Com a massificação da Internet nas duas últimas décadas e o advento das redes sociais, essas barreiras foram rapidamente vencidas. O número dos que apropriam do passado como bem entendem acende a cada segundo nesses novos ambientes cuja expansão aponta para o infinito (ELLIOT, 2017a, p. 7-9).

Juntamente com a pós-verdade, outro conceito está a ganhar presença cativa nos debates. Trata-se da autoverdade. ${ }^{4}$ Assim como a pós-verdade, a autoverdade não está preocupada com a qualidade e o embasamento dos argumentos propostos e/ou com quem os construiu, mas apenas em vencer uma contenda, em ter o controle a todo custo sobre as narrativas. Para isso, vale tudo: mentiras podem ser ditas e reditas, curtidas e compartilhadas sem remorso algum. O importante é a vitória absoluta do eu sobre todos os outros eus. Inebriado pelas próprias convicções, aquele é incapaz de se conectar com outros que tenham opiniões diferentes e confrontar os próprios conhecimentos prévios. Alimentada pelo narcisismo próprio da cultura da vaidade que igualmente cresce entre nós, a barbárie interior de um eu sozinho vocifera contra qualquer um que tente arrancá-la de sua caverna para expô-la à luz do conhecimento.

\section{Usos do passado medieval, uma nova velha história}

$\mathrm{Na}$ esteira deste longo e tortuoso processo, vemos emergir das redes sociais um novo regime de historicidade. Para lá de pós-moderno, ele usa e abusa de fragmentos do passado para construir (ou destruir) narrativas com objetivos absolutamente presentistas e voltados para o desejo de ter em mãos a última palavra, ou melhor, o último comentário. Depois de um longo flerte com o relativismo, a verdade tornou-se descartável, ultrapassada, figurante de fundo nas questões políticas, por exemplo. Com efeito, mais do que nunca, os dramas do presente e os argumentos de quem consome a fala ou a escrita pontuam a construção de uma memória histórica lançada com ares de autoridade sobre as mesas de debate sem a menor intenção de se abrir ao contraditório ou simplesmente pensar duas vezes antes de falar ou escrever. Verdades prontas nutridas por quantidades generosas de fatos alternativos que ousam negar $o$ holocausto e a escravidão, entre tantos outros exemplos possíveis. Certamente, os historiadores e outros pesquisadores do futuro encontrarão um rótulo adequado para denominar a época na qual vivemos. Idade da (Des)Informação é a sugestão que aqui singelamente deixo.

Neste contexto tomado por rompantes de razão delirante e ética seletiva, como estudioso da Idade Média, percebo uma crescente retomada dos usos do passado medieval por aqueles que adoram torturar e sacrificar a História nos recém construídos altares da pós-verdade, da direita à esquerda. Como dissemos, desde pelo menos o século XV, os usos depreciativos do medievo são conhecidos. Contudo, no atual século, em função do distanciamento temporal e do desconhecimento acerca das inúmeras pesquisas especializada sobre o período histórico em questão por parte do grande público, esses usos (e abusos, evidentemente) ganharam novas cores e possibilidades quase que infindáveis de disseminação. Estas servem para fomentar toda sorte de

\footnotetext{
${ }^{3}$ Os nazistas manipularam até mesmo os estudos sobre a Antiguidade eliminando qualquer traço indicativo da presença história da culturas de origem semita. Com isso, recriaram nas páginas dos livros de então uma Grécia de tez ariana completamente esvaziada de quaisquer elementos que pudessem sugerir trocas culturais - Cf. Bernal, 2005, p. 13-31.

${ }^{4}$ Cf. Brum, 2018a e 2018b.
} 
preconceitos e insanidades e encontraram na organicidade invisível dos já mencionados algoritmos a segurança para trafegar em qualquer direção. Ninguém está livre desta ameaça.

Como anteriormente sugerido, os usos do passado a partir de apelos midiáticos não representam exatamente uma novidade. Uma vez mais, um exemplo oriundo da Alemanha nazista. O III Reich (1933-1945) foi pródigo neste tipo de manipulação. Entre os antiquistas do regime, o apagamento de qualquer traço da presença semítica na história foi procedimento fartamente difundido (BERNAL, 2005, p. 13-31). Um dos diversos símbolos deste pensamento então reinante foi o quadro $O$ porta estandarte (Imagem 1) do pintor austríaco Hubert Lanzinger (1880-1950) que hoje se encontra no Centro de História Militar do Exército dos Estados Unidos (US Army Center of Military History), na cidade de Washington (EUA). Ao representar o Führer Adolf Hitler (18891945) com a armadura de um cavaleiro teutônico a segurar com a mão direita a bandeira em vermelho e branco do partido nazista, a imagem manipula o passado e traz uma verdade que emociona ao produzir naqueles que a observam uma espécie de orgulho retrospectivo diante de uma passado glorioso resgatado pelo presente renovador e que promete ser o início de um futuro igualmente glorioso (ELLIOT, 2017b). Na verdade, essa imagem pouco ou nada tem a dizer sobre o passado dos cavaleiros teutônicos ou da própria Alemanha. Os resultados nefastos dessa manipulação, desse fake transformado em verdade pela força da maioria enfeitiçada pelo impacto visual, são mundialmente conhecidos como um dos capítulos mais sombrios da história da humanidade.

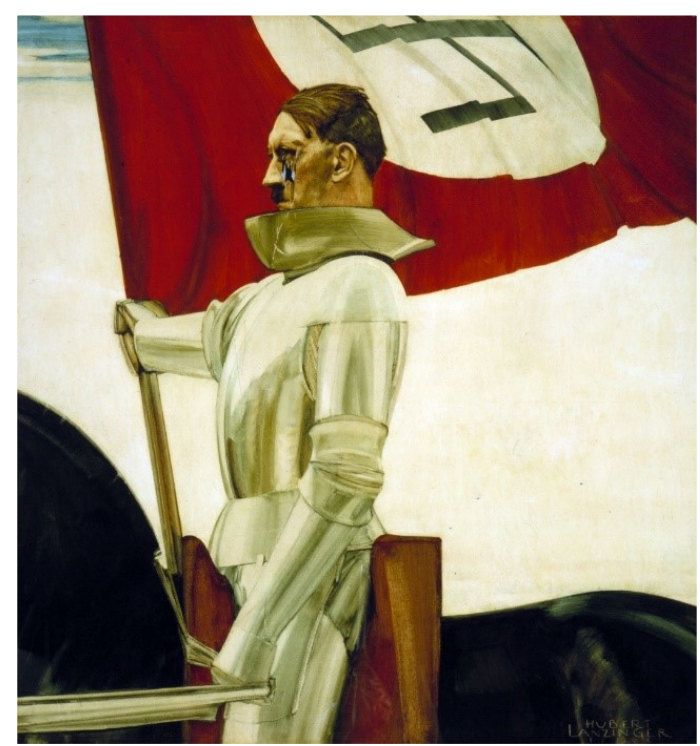

Imagem 1: O porta estandarte. Hubert Lanzinger (1880-1950), óleo sobre madeira, c.1934-1936. ${ }^{5}$

Recentemente, grupos de jovens extremistas saíram às ruas de várias cidades inglesas a portar escudos e capacetes em reverência a antigos cavaleiros e guerreiros medievais. Muitos deles são membros de uma organização de extrema direita conhecida como EDL - English Defence League (Liga de Defesa Inglesa, em tradução livre para a Língua Portuguesa) cujo objetivo central é proteger o Reino Unido de uma suposta invasão islâmica (ELLIOT, 2017b, p. 155-152). Para algum desavisado, as

5 Disponível em <https://alias.estadao.com.br/noticias/geral,desprezo-de-hitler-pela-democracia-e-umaviso-para-os-dias-de-hoje,70002470717.amp> 
manifestações em praça pública em plena luz do dia poderiam ser uma espécie de encenação folclórica ou alguma festa a reverenciar ancestrais locais. Nada disso. $\mathrm{Na}$ verdade, tratava-se de mais um dos numerosos episódios de pura intolerância que se propagam pela Europa no rastro de pessoas que se veem como herdeiros de uma ancestralidade linear que se encontra ameaçada por estrangeiros recém-chegados e tratados como hostis aos valores da civilização ocidental. Misturada às incertezas provocadas por crises econômicas que promovem desemprego e queda da renda de muitos trabalhadores, esse tipo de comportamento é gerador de medo e incertezas que podem ferir tanto psicológica quanto fisicamente. ${ }^{6}$

Quase à mesma época dos eventos em território inglês, mais especificamente em agosto de 2017, o mundo acompanhou o desenrolar de uma raivosa manifestação na pequena cidade de Charlotesville, na parte central da costa leste dos Estados Unidos, no estado da Virgínia. A portar escudos, capacetes e tochas semelhantes aos encontrados em iluminuras e filmes que retratam a Idade Média, os membros da manifestação formada majoritariamente por homens jovens e brancos ganhavam as ruas. Em uníssono, entoavam cânticos racistas que expressavam seu ódio contra minorias a residir na cidade. Aos pés da estátua do General Robert E. Lee (1807-1870), um personagem importante no contexto da Guerra Civil Americana (1861-1865) e um herói para os supremacistas, os confrontos com a polícia e representantes da população negra, LGBT, islâmica e hispânica considerados invasores foram inevitáveis. Uma pessoa acabou morta ao ser atropelada por um simpatizante do primeiro grupo. ${ }^{7}$

Em se tratando de Estados Unidos da América, os usos do passado medieval ou de resquícios oriundos de culturas medievais com olhos fixos no presente e na construção de discursos de cunho exclusivista também não são exatamente uma novidade própria do século atual. Construída entre os anos de 1858 e 1878, a catedral de São Patrício (St. Patrick's Cathedral) (Imagem 2), situada na região central de Nova York, próxima do Rockefeller Center, traz em sua imponente fachada uma nítida influência da arquitetura gótica dos séculos XII e XIII. Assim como outras construções espalhadas pela cidade, não se trata de uma mera coincidência ou homenagem despretensiosa ao velho mundo, lugar de onde vieram os primeiros colonos ingleses no distante século XVII. Na verdade, trata-se de uma maneira pouco discreta de exaltar a supremacia de uma determinada civilização a partir de uma identidade cristã branca cristalizada na paisagem da cidade que é conhecida como a "Capital do Mundo". Identidade cristã branca exaltada para asseverar que as terras ocupadas ainda no período colonial eram dos cristãos que ali chegaram e se estabeleceram a impor um estilo de vida por eles considerado melhor, mais evoluído que os nativos, em outras palavras, civilizado. Portanto, por razões hierárquicas e científicas, religiosas e culturais, índios e negros, ou seja, gente portadora de uma ancestralidade diferente, deveriam procurar outros lugares para viver ou se submeter aos desígnios impostos pelas elites locais. Elites que se apropriaram dessas concepções ideológicas para afirmar sua posição no interior do sistema colonial. ${ }^{8}$ Neste caso, a medievalidade, assim como na

\footnotetext{
${ }^{6}$ A respeito desta questão, as palavras de François Dosse são precisas: "Os períodos de crise são especialmente propícios ao entrelaçamento das temporalidades para garantir o avanço de um mundo novo, que se reassegura e se legitima através de tempos passados". Cf. Dosse, 2013, p. 326.

7 Informações obtidas nos seguintes endereços eletrônicos: <https://www.bbc.com/portuguese/brasil40913908>, <https://brasil.elpais.com/brasil/2017/08/12/album/1502552919_477485.html\#foto_gal_25>e <https://brasil.elpais.com/brasil/2017/08/12/internacional/1502553163_703843.html?rel=mas>. Acesso em 13 de outubro de 2018.

${ }^{8}$ Cf. Barrington, 2016, p. 182; Bethencourt, 2018, p. 374.
} 
Inglaterra e nas ruas da pacata Charlotesville, assumiu ares de superioridade: marca identitária e nostálgica de um grupo que se considerava melhor.

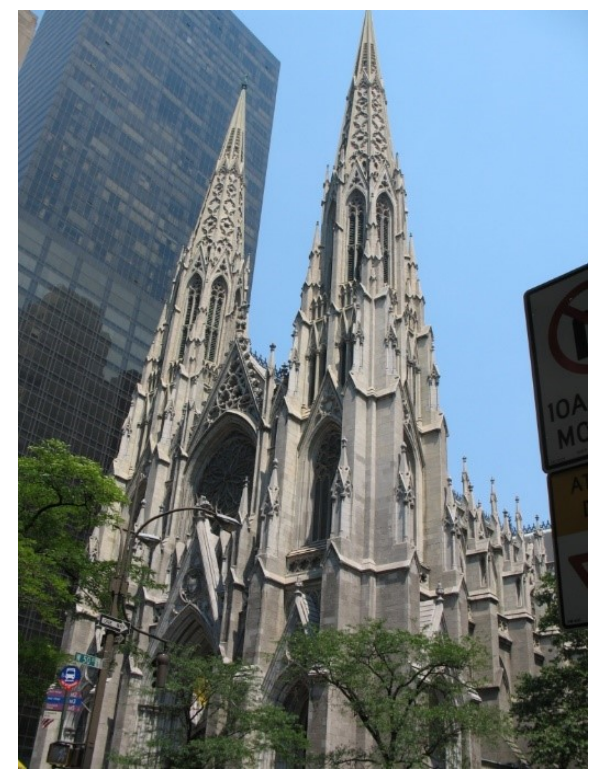

Imagem 2: Vista frontal da Catedral de São Patrício em Nova York ${ }^{9}$

$\mathrm{Na}$ busca por uma referência complementar geograficamente próxima e com significado análogo, acredito que uma importante edificação de Cuiabá tem muito a nos dizer. Construída entre os anos de 1928 e 1956 - a "Notre-Dame cuiabana", como é popularmente conhecida -, a Igreja Nossa Senhora do Bom Despacho (Imagem 3), repousa imponente sobre a paisagem do centro da capital de Mato Grosso. Reconhecida como patrimônio histórico e cultural da cidade desde 1977, suas linhas inspiradas na arquitetura gótica medieval ajudam a ocultar a diversidade cultural da população mato-grossense em benefício de uma história narrada como pacífica e linear: a dos conquistadores cristãos de pele clara de origem europeia. Assim, a reconstrução inspirada no medievo em concreto e vitrais coloridos no sertão brasileiro ajuda esconder os diversos dramas de grupos indígenas e trabalhadores negros cujas memórias sucumbiram diante da imposição de uma memória homogênea. Uma unidade narrativa de nítidas feições ideológicas que se sobrepôs à diversidade cultural e étnica dos matogrossenses. Em silêncio, dia e noite, assim como a Catedral de Nova York, as paredes e colunas da edificação cuiabana exaltaram e ainda exaltam o homem branco cristão e sua imaginada ancestralidade europeia. ${ }^{10}$ Patrick\%27s_Cathedral_New_York_2006-06-18.JPG>.

${ }_{10}$ Para os exemplos apresentados, as palavras de Margaret MacMillan são absolutamente esclarecedoras e reforçam as assertivas de Keith Jenkins e Eric Hobsbawm apresentadas no início deste artigo: "O passado pode ser aproveitado para quase tudo que se queira fazer no presente. Nós o menosprezamos quando mentimos sobre ele ou quando escrevemos histórias que mostram apenas um de seus lados. Podemos pôr em prática o que aprendemos tanto de um modo cuidadoso quanto desastroso. Isso não significa que somos capazes de ver a história como fonte de conhecimento, apoio e ajuda, mas que devemos ter cautela com o emprego que fazemos dela" (MACMILLAN, 2010, p. 11). 


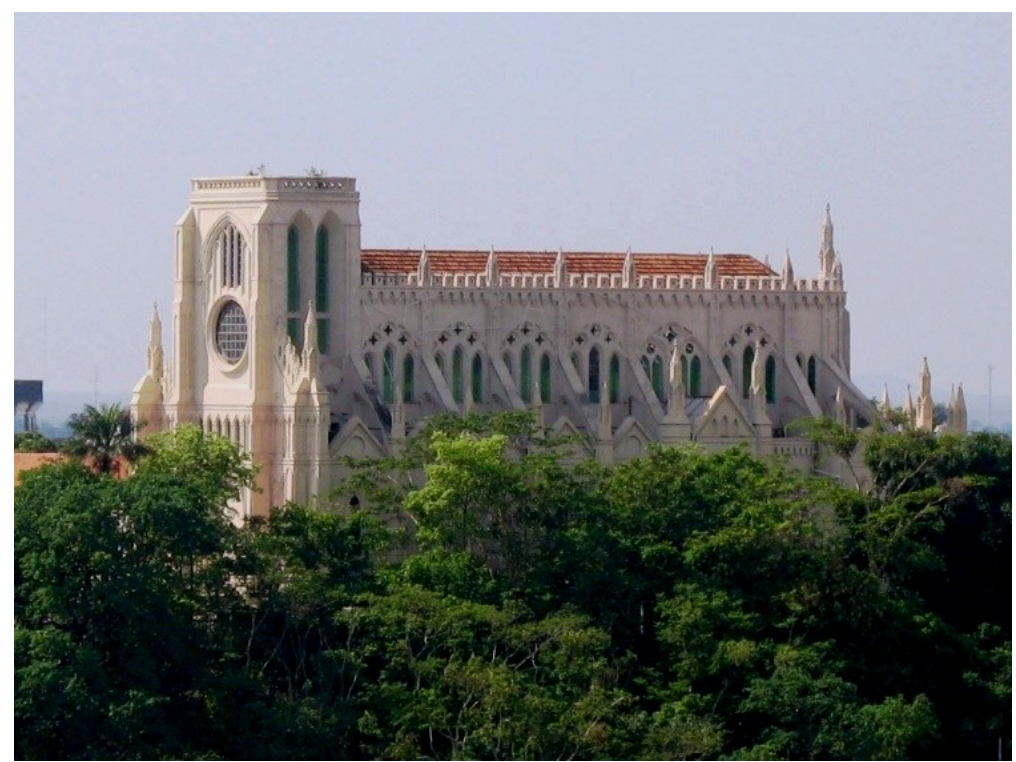

Imagem 3: Visão panorâmica da Igreja Nossa Senhora do Bom Despacho, em Cuiabá (MT) ${ }^{11}$

Como tantos outros encontrados de norte a sul do continente americano, esses dois exemplos de construção me fazem pensar na disseminação de determinadas percepções acerca do medievo em caráter global. E essa disseminação diz muito acerca de como a Idade Média foi recebida e ressignificada em contextos coloniais e póscoloniais que estavam a se formar muito além da Europa. Em muitos casos, o objetivo velado foi o de criar um senso de diferenciação reforçado na exaltação de origens europeias compartilhadas. De fato, tal leitura obtusa sobre o medievo prosperou porque representantes das elites locais se colocaram em uma posição intelectualmente privilegiada. Em busca de legitimidade e autoridade, esta posição Ihes permitiu escrever e ensinar uma história contínua da qual tomaram para si o quinhão mais valioso. Enfim, continuidade histórica forçada que lhes pôs no colo a condição de herdeiros únicos de um capital cultural elevado e que os conectou quase que naturalmente ao modelo civilizacional europeu (BARRINGTON, 2016, p. 184-189).

Sem perder o fio da meada, passo do concreto armado a céu aberto para o mundo virtual no qual está o nosso último exemplo. Em um pequeno vídeo publicado no dia 25 de novembro de 2017 em um canal do YouTube conhecido como Mitadas da direita, o filósofo Allan dos Santos apresentou uma fala de pouco mais de 11 minutos. Seu objetivo: "explicar" o que é a cultura ocidental. Por si só, o título escolhido para a postagem no mínimo controversa é bem sugestivo: O que é a civilização? Desenhando fica mais fácil? ${ }^{12}$ Com uma caneta-pincel em punho, Santos, que se define como um homem católico de direita e um fiel eleitor-seguidor do à época deputado federal pelo estado do Rio de Janeiro, Jair Messias Bolsonaro, distribuiu suas "certezas" sobre uma lousa branca fixada na parede ao fundo do local da filmagem. Com ar professoral, barba grisalha, óculos de armação grossa e uma fala agressiva marcada por palavras de baixo calão ditas ao final das frases proferidas, ele apresentou seus argumentos acerca do que concebia como civilização, sempre no singular. Sem citar o nome de um único autor ou pelo menos títulos de livros ou artigos previamente consultados, Santos teceu frases

\footnotetext{
${ }^{11}$ Disponível em https://olhares.sapo.pt/igreja-cuiaba-foto1781410.html.

12 O vídeo está disponível na Internet no seguinte endereço eletrônico $<$ https://www.youtube.com/watch?v=RV_PVYpTjHA>.
} 
como: "A civilização foi da Europa para o mundo". Civilização esta que para ele se assentava sobre três pilares geográficos: Atenas, Roma e Jerusalém, cidades a representar, respectivamente, a filosofia, o direito e a cultura judaico-cristã. $\mathrm{Na}$ acepção de Allan dos Santos, ali estava toda a estrutura que permitiu o progresso do mundo ocidental (celular, tablet, Internet etc.), pois para ele a civilização é o ocidente, e o ocidente é a civilização. Simples assim.

Acessado cerca de duas mil e quinhentas vezes à época de minha consulta, o vídeo naturaliza conceitos polêmicos e complexos como "ocidente" e "civilização". Do início ao fim, é uma ode monocórdica ao eurocentrismo que hoje segue anos luz de distância de uma nova historiografia cada vez mais atenta às longevas conexões entre Europa, África e Ásia. Conexões estas que revelam de maneira contundente que o protagonismo europeu é muito recente na História da humanidade e a tentativa de projetá-lo nas águas profundas do passado diz muito mais sobre as relações de força que se formaram em épocas recentes do que algo que existiu desde sempre. Ademais, a argumentação simplista e preconceituosa de Allan dos Santos uma vez mais rouba sem o mínimo de pudor as histórias de outros povos e culturas e reforça o olhar imperialista do colonizador branco europeu, ainda que na prática o colonialismo tenha acabado há tempos (GOODY, 2008, p. 11-36).

Recheados de informações imprecisas ou mesmo de mentiras grosseiras, vídeos como este se espalham pela redes sociais e alcançam pessoas comuns que passam a atropelar o conhecimento em prol de opiniões tomadas pelas referidas pósverdade e da autoverdade. ${ }^{13}$ Infelizmente, como evidenciado em páginas anteriores, os acessos, os compartilhamentos e as curtidas têm um alcance e um poder de convencimento muito maior que bons livros que resultam de anos de dedicação à pesquisa. Tudo isso me faz compreender situações nas quais o negacionismo puro e simples, como no caso do holocausto judaico ou da escravidão africana, para ficar em dois exemplos, põe abaixo décadas de estudos realizados com maturidade e rigor. ${ }^{14}$ Aos abnegados que ousam fazer diferente, pensar fora da caixa, como costumam dizer por aí, a barbárie da razão delirante exibe seus caninos raivosos a recusar um passado que não seja exatamente igual ao seu presente (TODOROV, 2010, p. 135). Assim, a busca por um passado compreendido como puro, de feições arianas, como um dia desejaram os nazistas, torna-se a justificativa perfeita para não aceitar a presença de estrangeiros em um território ou país. Tudo isso torna urgente o atendimento ao chamado do professor Gabor Klaniczay feito em 2011 no International Medieval Congress realizado na cidade de Leeds (Inglaterra) que utilizei como epígrafe e que aqui novamente escrevo: "Se não estudamos a Idade Média, e não tentamos entende-la e explicá-la de uma maneira imparcial, deixaremos então o campo aberto para aqueles que abusam e exploram o passado para justificar injustiças modernas" (KLANICZAY, 2017, p. 3).

Portanto, os historiadores e outros profissionais de áreas afins devem novamente se fazer presentes e tomar assento nos debates públicos, sobretudo naqueles que se referem aos usos do passado medieval, uma vez que a Idade Média

\footnotetext{
${ }^{13}$ Como em um artigo assinado por Patricia R. Blanco na versão on line do jornal El pais no qual é criticada a postura manipuladora daqueles que negam sem sustentação documental a presença árabe-islâmica na Península Ibérica e, consequentemente, na Europa. Postura que Blanco definiu como "fraude historiográfica". Informações obtidas em https://elpais.com/elpais/2018/04/06/hechos/1523043230_705992.html?id_externo_rsoc=FB_CM. Acesso em 18 de outubro de 2018.

14 Cf. Vidal-Naquet, 1988.
} 
novamente está a ser pilhada. Na ótica de Andrew B. R. Elliott, pesquisador que há tempos se dedica a estudar as relações intrincadas entre História, política e as mídias de massa, a sensação passiva de que o medievo foi absolutamente branco e cristão talvez tenha sido o grande equívoco interpretativo dos medievalistas ao longo dos séculos XIX e XX. Tal percepção ganhou o mundo. Mesmo que de uma maneira muitas vezes inconsciente, acabaram por oferecer farta munição a discursos extremistas (ELLIOT, 2017a). Ainda de acordo com o referido pesquisador inglês, as novas mídias digitais, diferente da pintura e da literatura em épocas passadas e do cinema em períodos mais recentes, foram poderosamente democratizadas e, como consequência, também multiplicaram o poder daqueles que usam o passado medieval para dar autoridade e legitimidade às bandeiras ideológicas que desfraldam em praça pública e, sobretudo, no mundo virtual (ELLIOT, 2017b, p. 7).

$\mathrm{Na}$ Europa, e mais recentemente no Brasil, estudos voltados para as trocas culturais afastadas de laivos nacionalistas tem sido uma tendência que se desenvolve a olhos vistos. A certeza de que não existe uma única história da Europa, mas histórias múltiplas dentro da Europa e uma Europa conectada com a África e a Ásia é uma nova abordagem que tem se mostrado como uma ferramenta poderosa no processo de desconstrução das falas extremistas. Portanto, uma nova História para o século XXI exige que novas perguntas sejam feitas ao passado. Perguntas que levem em consideração o que têm a dizer as vozes até então rotuladas como periféricas. Todavia, o alcance de tais propostas manter-se-á reduzido caso permaneçam delimitadas por antigas linguagens acadêmicas. A autocrítica neste quesito também se faz urgente.

Recentemente, o professor Jurandir Malerba, da Universidade Federal do Rio Grande do Sul (UFRGS), fez um importante alerta: a História tal como conhecemos, ensinamos e escrevemos pode estar em vias de extinção (MALERBA, 2007, p. 1-20). De acordo com a argumentação provocativa de Malerba, o descompasso entre os historiadores e as novas linguagens fomentadas pela Internet permitiram que novos públicos emergissem ávidos por informações cujos antigos meios de divulgação, sobretudo os acadêmicos, não mais são suficientes para atendê-los. Se os antigos suportes do conhecimento não forem repensados, qualquer aventureiro das redes sociais terá uma capacidade de penetração nas entranhas do tecido social infinitamente maior que a de historiadores, sociólogos, filósofos, jornalistas etc. Na esteira deste imbricado processo que trouxe para debate e com base neste importante alerta, a História e as demais Ciências Humanas que desejamos para o século XXI não podem ignorar as novas linguagens que estão a surgir e também não podem ignorar a importância dos estudos de História medieval e dos medievalistas para a construção de exposições argumentativas públicas saudáveis e frutíferas, pois, com o olhar voltado para a longa duração e as longas e múltiplas conexões, também somos capazes de perceber que o passado é rico e diverso e ele apenas reproduz o hoje quando torturado por verdugos presentistas. Com isso, ganha o conhecimento, ganha a sociedade, ganha a democracia.

Entre os princípios da retórica antiga que chegaram até a Idade Média estava a necessidade de falar de acordo com o público. Assim, diante de pessoas mais simples e sem conhecimentos letrados, o retórico deveria ser direto e utilizar metáforas para dar clareza aos assuntos tratados. Diante de plateias mais preparadas e capazes de 
compreender elucubrações profundas em função de seus conhecimentos prévios, o retórico lançaria mão de outras habilidades e conteúdos. Em ambos os casos, o princípio ético da verdade estava posto como um norte. Fonte de conhecimentos hoje esquecidos, as culturas antiga e medieval ainda têm muito a nos dizer. Se historiadores afeitos às luzes do sucesso discursam de acordo com as demandas dos públicos que os buscam (e pagam cachês generosos), se muitos manipulam o passado a seu bel prazer e o depositam nas redes sociais na forma de memes e similares, acredito que seja o momento de reafirmar a História como uma importante área de conhecimento sem hierarquizar suas subáreas temáticas e buscar em cada uma o que podem oferecer de melhor na esperança de encontrar uma verdadeira História pública e não meramente uma História para o público.

Quem usa o passado deseja simplificá-lo, reduzi-lo a dimensões que se encaixem em modelos ideológicos pré-fabricados. E quem usa o passado rompe com a velha premissa de que a História é mestra da vida. Como afirmei em parágrafos precedentes, transformado em conhecimento histórico a ocupar as páginas dos livros, revistas e outros meios de comunicação, o passado ensina em um processo contínuo de abertura ao outro em lugares e tempos diferentes. Caminhar na direção contrária, como infelizmente muitos já fizeram, é torná-lo servo de nossas ideias, é tomá-lo de maneira mesquinha. Não, ele não é o culpado por nossos problemas. Uma vez mais: pilhar o passado e tomá-lo como selo de legitimidade para discursos de cunho políticoideológico no presente é o que não podemos aceitar, tanto no real quanto no virtual. Ainda que poucos estejam dispostos a nos ouvir, o silêncio não é uma opção.

\section{Uma conclusão, ainda que parcial...}

Se na abertura deste ensaio tomei de empréstimo as palavras de dois historiadores há tempos conhecidos pelo público brasileiro, para encerrá-lo lanço mão das propostas de dois filósofos contemporâneos que começaram a marcar presença em nosso meio acadêmico: Martha Nussbaum (2015) e Nuccio Ordine (2016). Ambos escreveram sobre a importância das Ciências Humanas não apenas em âmbito universitário, mas nas vidas de todos nós, crianças, jovens e adultos, homens e mulheres. Com Nussbaum e Ordine no radar, confio que a diversidade presente nos estudos de História e em específico nos estudos de História medieval é um convite ao encontro com a alteridade a partir de esforços cognitivos profundos capazes de privilegiar o que há de melhor na subjetividade humana, independente dos recortes espacial e temporal escolhidos. Como prêmio, esta se afasta dos sorrisos faceiros da pós-verdade e da autoverdade que mal escondem suas rugas sulcadas pela decrepitude da razão delirante e de uma moral provisória. Ao mesmo tempo, as ideologias dos supremacistas e dos utilitaristas que se querem dominantes perdem sua razão de ser.

Por fim, da defesa e valorização das Ciências Humanas como um todo deriva minha preocupação com a ampliação da atuação dos medievalistas no espaço público. Para tanto, não poderemos agir como ilhas isoladas, mas como arquipélagos que se conectam pelas trocas na intenção de transmitir e, sobretudo, produzir conhecimentos e que estes não estejam voltados apenas para os públicos de sempre. Que nestes novos contextos formados por novas perguntas direcionadas ao passado e novos meios de divulgação do conhecimento, os medievalistas saibam também agir de forma crítica e criativa contra a feitura e disseminação de uma História da Europa com traços nacionalistas e cristãos uniformizados sempre a girar ao redor dos mesmos eixos 
interpretativos. Enfim, como defendeu Michael Borgolte (2017, p. 78-79), uma História que de fato se permita ser global e que leve em consideração os encontros e conflitos entre as pessoas, as culturas e as religiões na longa duração e nas amplas extensões que suscitaram múltiplas redes transculturais espalhadas pelo mundo. Aos que desejam encarar os desafios da renovação, as searas estão abertas. Há muito trabalho, mas a colheita pode ser boa.

\section{Referências}

BARRINGTON, Candace. Global medievalism and translation. In: D'ARCENS, Louise (ed.). The Cambridge companion to medievalism. Cambridge: Cambridge University, 2016.

BETHENCOURT, Francisco. Racismos: das cruzadas ao século XX. São Paulo: Cia. das Letras, 2018.

BERNAL, Martin. A imagem da Grécia Antiga como uma ferramenta para o colonialismo e para a hegemonia europeia. In: FUNARI, Pedro Paulo A. Repensando o mundo antigo. 2. ed. Campinas: IFCH/Unicampi, 2005.

BOLGOLTE, Michael. A crisis of the Middle Ages? Deconstructing and constructing European identities in a globalizes world. In: LOUB, Graham A. \& STAUB, Martial (eds.). The making of medieval history. York: York Medieval Press, 2017.

BRUM, Eliane. Bolsonaro e a autoverdade: como a valorização do ato de dizer, mais do que o conteúdo do que se diz, vai impactar a eleição no Brasil. Disponível em: $<$ https://brasil.elpais.com/brasil/2018/07/16/politica/1531751001_113905.html>. Acesso em 26 de julho de 2018a.

BRUM, Eliane. Como resistir em tempos brutos: um manual para enfrentar as próximas três semanas e transformar luto em verbo. Disponível em: <https://brasil.elpais.com/brasil/2018/10/08/opinion/1539019640_653931.html?fbclid=I wAR2HAKxhS6ipm9HW4USXDUm0102a2ve2MU975hol7143kjzXzhffo_9-ViM>. Acesso em 20 de outubro de 2018b.

D'ANCONA, Matthew. Pós-verdade: a nova guerra contra os fatos em tempos de fake news. Barueri: Faro, 2018.

DOSSE, François. Renascimento do acontecimento - um desafio para o historiador: entre a Esfinge e a fênix. São Paulo: Unesp, 2013.

ELLIOTT, Andrew B. R. Medievalism, politics and mass media: appropriating the Middle Ages in the twenty-first century. Cambridge: D. S. Brewer, 2017a.

ELLIOTT, Andrew B. R. A vile love affair: right wing nationalism and the Middle Ages. Disponível em <http://www.publicmedievalist.com/vile-love-affair/>. Acesso em 26 de junho de 2017b.

GOODY, Jack. O roubo da História: como os europeus se apropriaram das ideias e invenções do Oriente. São Paulo: Contexto, 2008.

HOBSBAWM, Eric. Sobre História. São Paulo: Cia. das Letras, 1998.

JENKINS, Keith. A história refigurada: novas reflexões sobre uma antiga disciplina. São Paulo: Contexto, 2017. 
KLANICZAY, Gabor adaptado por LOUB, Graham A.; STAUB, Martial (eds.). The making of medieval history. York: York Medieval Press, 2017.

MACMILLAN, Margaret. Usos e abusos da história. Rio de Janeiro / São Paulo: Record, 2010.

MALERBA, Jurandir. Os historiadores e seus públicos: desafios ao conhecimento histórico na era digital. Revista Brasileira de História, São Paulo, 2017.

NUSSBAUM, Martha. Sem fins lucrativos: por que a democracia precisa das humanidades. São Paulo: Martins Fontes, 2015.

ORDINE, Nuccio. A utilidade do inútil: um manifesto. Rio de Janeiro: Zahar, 2016.

PARISER, Eli. O filtro invisível: o que a Internet está escondendo de você. Rio de Janeiro: Zahar, 2012.

VIDAL-NAQUET, Pierre. Os assassinos da memória: "Um Eichmann de papel" e outros ensaios sobre o revisionismo. Campinas: Papirus, 1988.

TODOROV, Tzvetan. O medo dos bárbaros: para além do choque de civilizações. Petrópolis: Vozes, 2010

WHEATCROFT, Andrew. Infiéis: o conflito entre a cristandade e o islã - 638-2002. Rio de Janeiro: Imago, 2002.

\section{Notas de autoria}

Carlile Lanzieri Júnior é professor Adjunto C Nível II do Departamento de História e do Programa de Pós-Graduação em História da Universidade Federal de Mato Grosso. Membro do Vivarium - Laboratório de Estudos da Antiguidade e do Medievo e do MAR - Medievalistas e Antiquistas em Rede. E-mail para contatos: lanzierijunior@uol.com.br.

Como citar esse artigo de acordo com as normas da revista

LANZIERI JÚNIOR, Carlile. O general, a catedral e o "filósofo": reflexões acerca do papel do medievalista diante de seus novos públicos. Sæculum - Revista de História, v. 24, no 41, p. 35-47, 2019.

\section{Contribuição de autoria}

Não se aplica.

\section{Consentimento de uso de imagem}

Não se aplica.

\section{Aprovação de comitê de ética em pesquisa}

Não se aplica.

\section{Licença de uso}

Este artigo está licenciado sob a Licença Creative Commons CC-BY. Com essa licença você pode compartilhar, adaptar, criar para qualquer fim, desde que atribua a autoria da obra.

\section{Histórico}

Recebido em 31/07/2019.

Aprovado em 16/09/2019. 